\title{
Mechanistic Study of the N-Formylation of Amines with Carbon Dioxide and Hydrosilanes
}

\author{
Martin Hulla, Gabor Laurenczy, ${ }^{\circledR}$ and Paul J. Dyson**i) \\ Institut des Sciences et Ingénierie Chimiques, École Polytechnique Fédérale de Lausanne (EPFL), CH-1015 Lausanne, Switzerland
}

Supporting Information

ABSTRACT: N-formylation of amines with $\mathrm{CO}_{2}$ and hydrosilane reducing agents proceeds via fast and complex chemical equilibria, which hinder easy analysis of the reaction pathways. In situ reaction monitoring and kinetic studies reveal that three proposed pathways, via direct- and amineassisted formoxysilane formation (pathways 1 and 2, respectively) and via a silylcarbamate intermediate (pathway 3 ), are possible depending on the reaction conditions and the substrates. While pathway 1 is favored for non-nucleophilic amines in the absence of a catalyst, a base catalyst results in

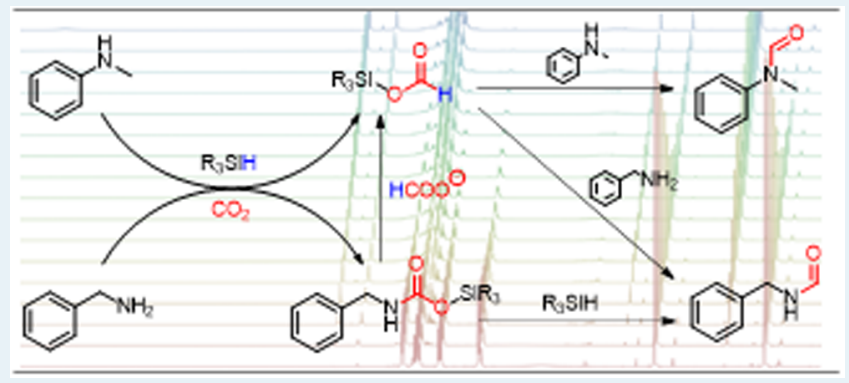
noninnocent behavior of the amine in the $\mathrm{CO}_{2}$ reduction step toward the formoxysilane intermediate. The reaction pathway is altered by strongly nucleophilic amines, which form stable adducts with $\mathrm{CO}_{2}$. Silylcarbamate intermediates form, which can be directly reduced to the $\mathrm{N}$-formylated products by excess hydrosilane. Nevertheless, without excess hydrosilane, the silylcarbamate is an additional intermediate en route to formoxysilanes along pathway 2. Exchange NMR spectroscopy (EXSY) revealed extensive substituent exchange around the hydrosilane silicon center, which confirms its activation during the reaction and supports the proposed reaction mechanisms. Numerous side reactions were also identified, which help to establish the reaction equilibria in the $\mathrm{N}$-formylation reactions.

KEYWORDS: carbon dioxide, reduction, $\mathrm{N}$-formylation, hydrosilane, ionic liquid, catalysis

\section{INTRODUCTION}

Amine reactions with $\mathrm{CO}_{2}$ and hydrosilanes have attracted considerable attention in recent years. ${ }^{1-3}$ Formamide, $\mathrm{N}$ methylamine, and aminal products are highly valuable building blocks in chemical synthesis. ${ }^{2,4}$ Moreover, $\mathrm{CO}_{2}$ is a cheap, nontoxic, and abundant $\mathrm{C} 1$ source ${ }^{5}$ and hydrosilanes are convenient, mild, and easy to use reducing agents (polymethylhydrosiloxane, PMHS, for example, is a waste product of the silicon industry and is inexpensive). ${ }^{6}$ Consequently, a large number of catalysts have been developed for this reaction, including simple metal salts, complexes based on $\mathrm{Rh}^{7} \mathrm{Ru},{ }^{8}$ $\mathrm{Re},{ }^{9} \mathrm{~W},{ }^{10} \mathrm{Cu},{ }^{11,12} \mathrm{Zn},{ }^{13,14}$ and $\mathrm{Fe},{ }^{15}$ and transition-metal-free catalysts such as carbenes, ${ }^{6,16-18}$ guanidines, ${ }^{19}$ zwitterionic Pylide- $\mathrm{CO}_{2}$ adducts, ${ }^{20}$ 1,3,2-diazophospholenes, ${ }^{21}$ carboxylates, ${ }^{22,23}$ carbonates, $^{24}$ ionic liquids, ${ }^{25,26}$ triazabicyclodecene (TBD), ${ }^{27,28}$ and $\gamma$-valerolactone. ${ }^{29}$ In addition, the solvents typically used, i.e. DMSO and DMF, are catalytically active. ${ }^{30}$ Interestingly, the organocatalysts can catalyze multiple $\mathrm{CO}_{2}-$ hydrosilane reactions leading to more than one of the aforementioned products or even all of them depending on the conditions employed. ${ }^{6,18,27,28,31}$

The observed selectivity, or lack thereof, generated interest in the reaction pathways that lead to the individual formamide, $\mathrm{N}$-methylamine, and aminal products. ${ }^{3}$ With $\mathrm{N}$-formylated products, most recent evidence suggests that three possible pathways can take place involving two different intermediates (Scheme 1). ${ }^{19}$ Pathway 1 involves direct reduction of $\mathrm{CO}_{2}$ by
Scheme 1. $\mathrm{N}$-formylation of Amines with $\mathrm{CO}_{2}$ and Hydrosilanes: (a) General Reaction Scheme and (b) Previously Proposed Reaction Pathways

a)

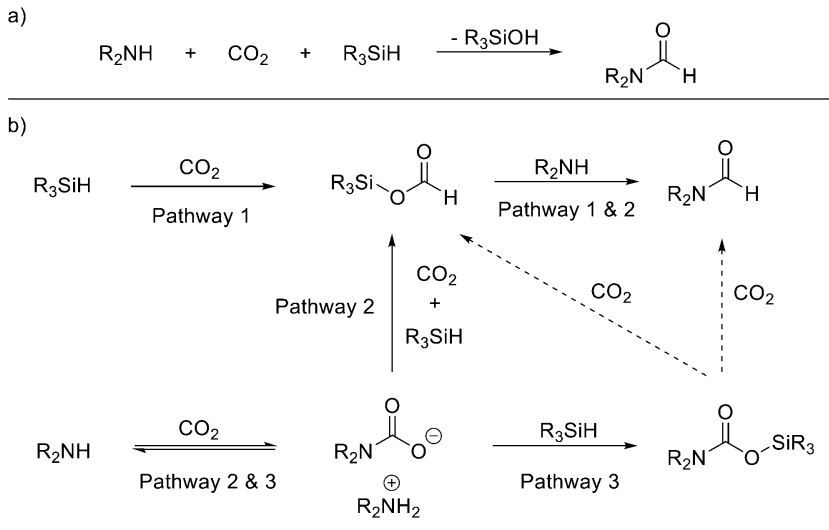

the hydrosilane, to form a formoxysilane intermediate, followed by a simple addition-elimination reaction with the amine to form the formamide product. Hydrosilane activation by a nucleophilic catalyst and $\mathrm{CO}_{2}$ reduction by a hypervalent silicon was proposed as the transition state (TS). ${ }^{22,24,26,31}$ The

Received: August 16, 2018

Revised: October 1, 2018

Published: October 4, 2018 
pathway is supported by DFT calculations ${ }^{32}$ and the isolation and reactivity of the formoxysilane intermediate. ${ }^{33}$ However, more recent DFT calculations suggest that this pathway is favored in the absence of a catalyst ${ }^{34}$ but otherwise is likely to be slow. ${ }^{19}$ Pathway 2 also involves a formoxysilane intermediate and its subsequent reaction with an amine to form the formamide product. However, its formation is dependent on a catalyst-stabilized carbamate salt, which activates the hydrosilane in a manner similar to that proposed for pathway 1 with a comparable TS. ${ }^{35}$ DFT calculations of the reaction mechanism with $\mathrm{NHC}$ and $\mathrm{ZnCl}_{2}$ catalysts indicate that the energy of pathway 2 is lower than that for pathway $1 .^{35,36}$ Nevertheless, on the basis of the $\mathrm{N}$-formylation of morpholine with phenylsilane and 1,1,3,3-tetramethylguanidine catalyst, stable carbamate salts react with phenylsilane to form a silylcarbamate, rather than the formoxysilane previously reported, pathway $3 .^{19}$ The silylcarbamate intermediate is then transformed to the formamide product in the presence of $\mathrm{CO}_{2}$, either via the formoxysilane or directly by a different mechanism. An alternative pathway, via water-sensitive silylamines, toward the silylcarbamate was also proposed ${ }^{30}$ but has since been ruled out as unfeasible under the reaction conditions normally employed and due to its extreme moisture sensitivity. ${ }^{19}$

Irrespective of the reaction pathway, it became apparent that the reaction proceeds by a series of fast and complex chemical equilibria. ${ }^{19}$ This complexity, combined with the instability of the intermediates, hinders identification of the reaction pathway. Difficulties with the gas-liquid binary system largely restricted mechanistic investigations to ex situ analysis of the reaction intermediates by ${ }^{1} \mathrm{H},{ }^{13} \mathrm{C}$, and ${ }^{29} \mathrm{Si} \mathrm{NMR}$ spectroscopy and FTIR spectroscopy or stepwise addition experiments. ${ }^{19,25,30,31}$ Hence, we decided to investigate and establish the chemical equilibria as well as the reaction kinetics involved in the $\mathrm{N}$-formylation reaction in situ using NMR spectroscopic techniques. The effects of the amine and hydrosilane on the equilibria as well as the reaction pathway were investigated, and finally, a number of conditions governing the reaction pathway and observed intermediates were identified.

Reactions were primarily carried out in DMSO- $d_{6}$ with $\mathrm{N}$ methylaniline and phenylsilane at $25{ }^{\circ} \mathrm{C}$ and 20 bar of $\mathrm{CO}_{2}$ pressure. However, other anilines as well as benzylamine and triethoxysilane were used to provide further insights. Low temperatures and high pressures were used to suppress the formation of $\mathrm{N}$-methylamines and aminal side products, which require higher temperatures and, on the basis of the pathways proposed, sequential reduction of $\mathrm{CO}_{2}$ by the hydrosilane. ${ }^{19,22,31}$ Tetrabutylammonium acetate ([TBA][OAc]) was selected as a representative oxygen-containing nucleophilic, $^{20,22-24}$ ionic liquid like, ${ }^{25,26}$ basic $^{19,27,28}$ catalyst.

\section{RESULTS AND DISCUSSION}

Pathway 1 and $\mathrm{CO}_{2}$-Hydrosilane Chemical Equilibria. In the absence of a catalyst, reduction of $\mathrm{CO}_{2}$ and the formation of the formoxysilane intermediate were identified by DFT calculations as the rate-determining step in the $\mathrm{N}$ formylation reaction of $N$-methylaniline with phenylsilane. ${ }^{34}$ Simultaneously, hydrosilane activation by nucleophilic catalysts was proposed as the modus operandi for a number of $\mathrm{N}$ formylation catalysts including NHCs, ${ }^{32}$ tetrabutylammonium fluoride $([\mathrm{TBA}][\mathrm{F}]),{ }^{26} \mathrm{Cs}_{2} \mathrm{CO}_{3}{ }^{24}$ glycine betaine, ${ }^{31}$ and various carboxylates $^{22}$ (Scheme 2). Clearly, the mechanism of $\mathrm{CO}_{2}$ reduction and the formation of the formoxysilane
Scheme 2. Pathway 1 for the $\mathrm{N}$-formylation of Amines: (a) Pathway 1 Reaction Scheme and (b) Proposed Mechanistic Cycle for the Rate-Determining $\mathrm{CO}_{2}$ Reduction Step

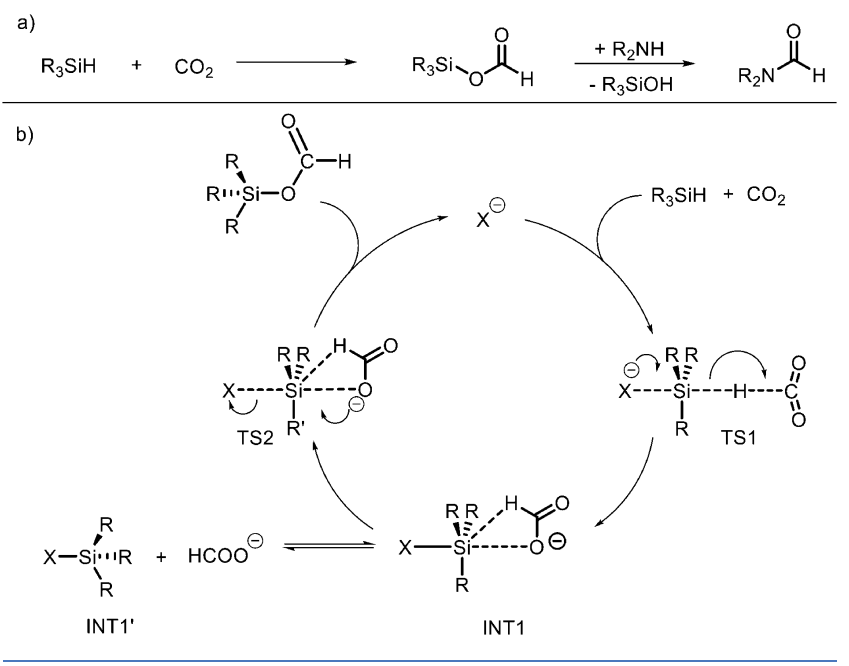

intermediate is key to understanding pathway 1 . In addition, all $\mathrm{N}$-formylation catalysts should catalyze the reduction of $\mathrm{CO}_{2}$ to formoxysilane (or formic acid after hydrolysis) in the absence of an amine. Notably, direct reduction of $\mathrm{CO}_{2}$ to formoxysilane was demonstrated with $\mathrm{NHC}^{37}$ and $[\mathrm{TBA}][\mathrm{F}]^{38}$ catalysts, which provided part of the basis for pathway 1 .

Experiments with [TBA] [OAc] $(10 \mathrm{~mol} \%)$ showed that the salt catalyzes $\mathrm{CO}_{2}$ reduction with phenylsilane, decreasing the reaction time from over $13 \mathrm{~h}$ to $<6 \mathrm{~h}$ (Figures S2 and S9), to afford a mixture of formoxysilanes, formic acid, and (in extremelly low yield) bis(silylacetals) and methoxysilane side products. ${ }^{37}$ Postreaction analysis of the reduction of $\mathrm{CO}_{2}$ with triethoxysilane by GC-MS also indicated the presence of tetraethoxysilane (vide infra) and various siloxanes, which could not be identified with certainty by NMR spectroscopy due to extensive overlap of the peaks. Formic acid probably results from formoxysilane hydrolysis due to trace water in the reaction solvent, as its concentration does not change after the first $30 \mathrm{~min}$ of reaction. Bis(silylacetals), methoxysilanes, and siloxanes are products from the reduction of formoxysilane with the hydrosilane. ${ }^{37}$ Silanols potentially produced by formoxysilane hydrolysis were not detected (Figure 1),

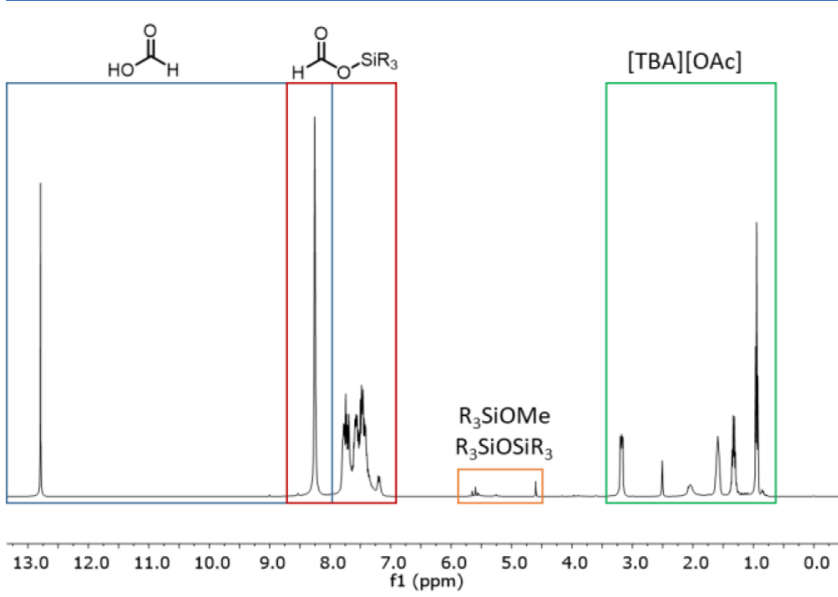

Figure 1. ${ }^{1} \mathrm{H}$ NMR spectrum of the reduction of $\mathrm{CO}_{2}$ with phenylsilane after $13 \mathrm{~h}$ (i.e., at the end of the reaction). 
Scheme 3. $\mathrm{CO}_{2}$ Reduction with Phenylsilane at 20 bar Pressure: (a) $\mathrm{CO}_{2}$ Reduction with Phenylsilane Reaction Scheme and (b) Observed Side Reactions

a)

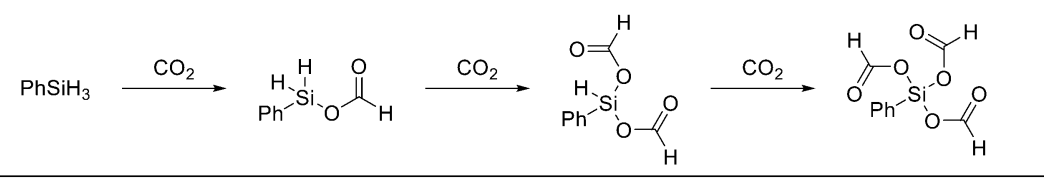

$$
\text { b) }
$$

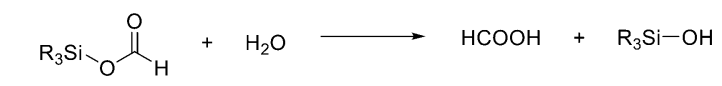

Scheme 4. Exchange Reactions That Take Place during the Reduction of $\mathrm{CO}_{2}$ with Hydrosilanes

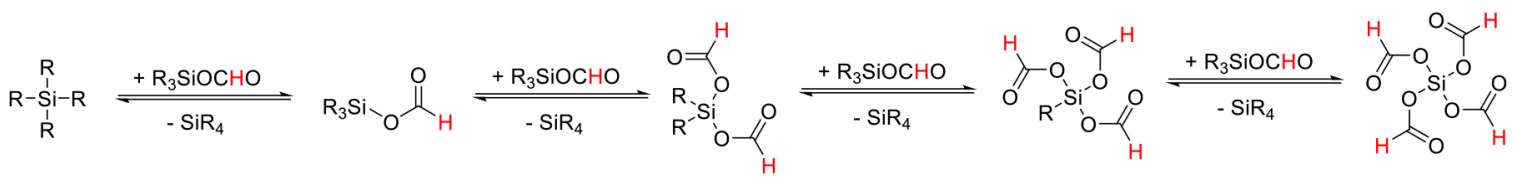

$$
\begin{aligned}
& \mathrm{R}_{3} \mathrm{Si}_{-} \stackrel{\mathrm{O}}{\mathrm{I}}_{\mathrm{H}}+\mathrm{HCOOH} \rightleftharpoons \mathrm{R}_{3} \mathrm{Si}{ }_{\mathrm{O}} \stackrel{\mathrm{O}}{\mu}_{\mathrm{H}}+\mathrm{HCOOH}
\end{aligned}
$$

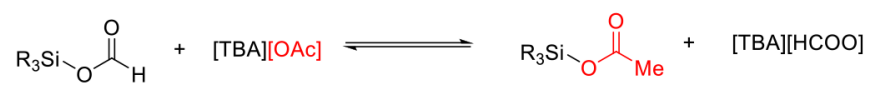

$$
\begin{aligned}
& \mathrm{HCOOH}+[\mathrm{TBA}][\mathrm{OAC}] \rightleftharpoons \mathrm{HOAC}+[\mathrm{TBA}][\mathrm{HCOO}]
\end{aligned}
$$

indicating that they react further with formoxysilanes to generate formic acid and siloxanes (Scheme 3). It should be noted that siloxanes can also be formed from the reaction of silanols with (unreacted) hydrosilane, generating hydrogen as the byproduct. $^{39}$ Considering that water is usually not rigorously excluded from $\mathrm{N}$-formylation reactions, it is highly probable that formic acid is formed and reduces the overall yield or at least the amount of hydrosilane available for reaction. Larger quantities of bis(silylacetals), methoxysilanes, and siloxanes could also be expected due to the lower pressures usually employed, decreasing the rate of formation of formoxysilane and increasing the rate of its reduction. ${ }^{19}$

The presence of formic acid in the reaction hinders accurate analysis of the formoxysilane(s) formed, as these are usually identified by a distinct formyl $(-\mathrm{CHO})$ proton signal in their ${ }^{1} \mathrm{H}$ NMR spectra. In the reaction of phenylsilane at $25{ }^{\circ} \mathrm{C}$ this signal overlaps with the signal from formic acid, resulting in a broad peak (Figure 1), which, however, moves from 8.24 to $8.16 \mathrm{ppm}$ as the reaction progresses. Hence, at $25^{\circ} \mathrm{C}$ in DMSO- $d_{6}$ the presence of formoxysilane is only indicated by the uneven integration of the acidic signal at $12.76 \mathrm{ppm}$ and the broad - CHO signal between 8.24 and $8.16 \mathrm{ppm}$.

Since broad signals are indicative of substituent exchange, the reaction mixture was gradually cooled to $218 \mathrm{~K}$ in DMF- $d_{7}$, confirming the presence of a dynamic exchange process between formic acid and formoxysilane(s). Surprisingly, the broad singlet attributed to - $\mathrm{CHO}$ splits into four different signals at $8.51,8.69,8.70$, and $8.74 \mathrm{ppm}$ rather than the expected two for formic acid and the formoxysilane $\mathrm{PhSi}$ $(\mathrm{OCHO})_{3}$ (Figures S3 and S4). Similar changes were observed in the ${ }^{13} \mathrm{C}$ NMR spectra, but only broadening of the peaks in the ${ }^{29} \mathrm{Si}$ NMR spectra is observed, indicating close proximity of multiple signals and/or continuous rapid exchange of the $\mathrm{Si}$ substituents. Incomplete conversion of phenylsilane to $\mathrm{PhSiH}$ $(\mathrm{OCHO})_{2}$ and $\mathrm{PhSiH}_{2}(\mathrm{OCHO})$ was ruled out by the absence of any $\mathrm{Si}-\mathrm{H}$ signals in both the ${ }^{1} \mathrm{H}$ and ${ }^{29} \mathrm{Si}$ NMR spectra (Figure S7), indicating the formation of other formyl species in solution. Large changes in the ${ }^{1} \mathrm{H}$ NMR spectra were also observed in the aromatic region and for the signals corresponding to the $[\mathrm{TBA}][\mathrm{OAc}]$ catalyst (vide infra). Exchange spectroscopy (EXSY) revealed interchange of the formyl groups between formic acid and the three other - $\mathrm{CHO}$-containing compounds as well as the exchange of phenyl groups between various species in solution (Figure S5). Even at $218 \mathrm{~K}$ the $-\mathrm{CHO}$ signals were broad and not fully resolved, confirming exchange on the NMR time scale and limiting the analysis. The full extent of the exchange was revealed with triethoxysilane (Scheme 4). Triethoxysilane can reduce one $\mathrm{CO}_{2}$ molecule to formoxysilane $\mathrm{EtO}_{3} \mathrm{SiOCHO}$. However, in DMSO- $d_{6}$ at room temperature, five peaks attributable to the $-\mathrm{CHO}$ moiety at $8.13,8.25,8.31,8.34$, and $8.35 \mathrm{ppm}$ gradually form, of which that at $8.35 \mathrm{ppm}$ was consumed during the course of the reaction and that at 8.13 ppm corresponds to the $\mathrm{C}-\mathrm{H}$ proton in formic acid. In DMF$d_{7}$ upon cooling to $218 \mathrm{~K}$ the remaining peaks were attributed to three different formoxysilanes (with peaks at 8.44, 8.54, and $8.59 \mathrm{ppm}$ ) as well as to formic acid (at $8.32 \mathrm{ppm}$ ). EXSY at $258 \mathrm{~K}$ showed exchange of the formyl group between formic acid and the formoxysilanes and also exchange among the various formoxysilanes (Figure 2). Due to extensive overlap of the peaks from the ethoxy substituents, exchange of these 


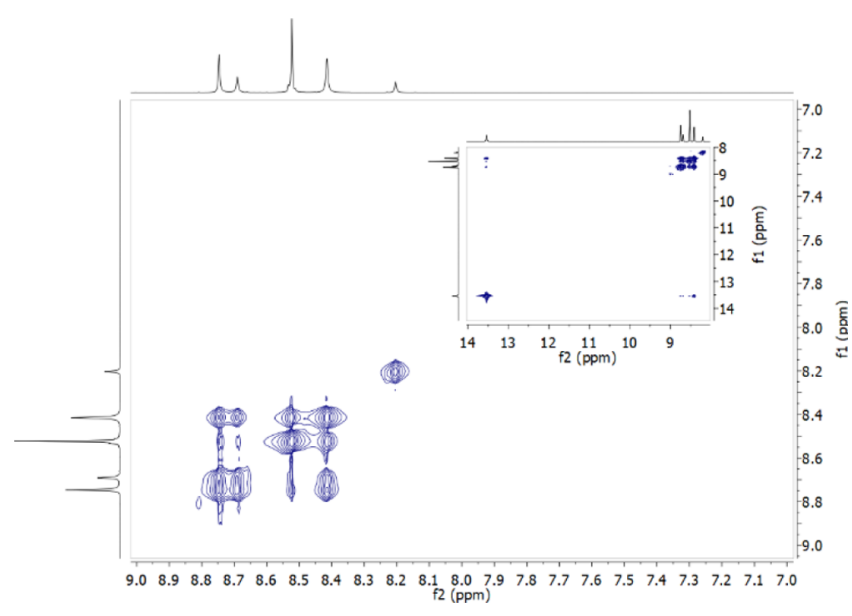

Figure 2. EXSY NMR spectrum of the products from the reaction of $\mathrm{EtO}_{3} \mathrm{SiH}$ and $\mathrm{CO}_{2}$ at $258 \mathrm{~K}$. For the full spectrum, see Figure S17.

groups could not be unambiguously confirmed but is implied by the large number of ethoxy signals and the detection of tetraethoxysilane (which gives peaks at 3.78 and $1.17 \mathrm{ppm}$ in the ${ }^{1} \mathrm{H}$ NMR spectrum and at $-82 \mathrm{ppm}$ in the ${ }^{29} \mathrm{Si}$ NMR spectrum). The presence of tetraethoxysilane was further confirmed by GC-MS at the end of the reaction. Finally, the formyl signals were assigned to formic acid, $\mathrm{R}_{3} \mathrm{SiOCHO}$, $\mathrm{R}_{2} \mathrm{Si}(\mathrm{OCHO})_{2}, \mathrm{RSi}(\mathrm{OCHO})_{3}$, and $\mathrm{Si}(\mathrm{OCHO})_{4}$, where $\mathrm{R}=$ $\mathrm{Ph}, \mathrm{EtO}$. The formation of these four formoxysilanes is accompanied by the simultaneous formation of $\mathrm{SiR}_{4}$, supported by the observed exchange of phenyl groups and confirmed by the formation of tetraethoxysilane.

Substituent exchange has been observed in the related hydrosilane reduction of carbonyls catalyzed by fluoride salts and bases. ${ }^{40}$ The reaction proceeds by hydrosilane activation with a nucleophilic catalyst and a five-membered hypervalent silicon intermediate. Similarly, a five-membered silicon intermediate was proposed for the hydrosilane reduction of $\mathrm{CO}_{2}{ }^{26}$ DFT calculations demonstrated that a related fivemembered TS, rather than an intermediate, is energetically favored in $\mathrm{CO}_{2}$ reductions. ${ }^{35}$ However, similar exchange behavior is still expected and confirmed by the EXSY experiments, further supporting the proposed reaction mechanism. Hence, a binuclear associative mechanism, ${ }^{40}$ possibly assisted by a bridging carboxylate anion, may be involved in the exchange process. In addition, the exchange can potentially be exploited for the preparation of highly reactive formoxysilanes from hydrosilanes of inherently low reactivity, similarly to the recently reported preparation of gaseous hydrosilanes from alkoxyhydrosilane surrogates in the reduction of alkenes. ${ }^{41}$

DFT calculations suggest that an off-cycle species may be derived en route to formoxysilane, in which the acetate anion attaches to the hydrosilane to eliminate a formate anion (INT1', Scheme 2). ${ }^{23}$ This behavior was observed with iridium trifluoroacetate complexes, where detachment of the ligand and its reaction with hydrosilane and $\mathrm{CO}_{2}$ resulted in partial catalyst deactivation. ${ }^{39}$ However, considering the substituent exchange process around the silicon center, a dynamic exchange of the acetate anion with the formate anion is expected with the $[\mathrm{TBA}][\mathrm{OAc}]$ catalyst. Indeed, with phenylsilane the acetate peak broadened and shifted to higher frequency during the reaction. Upon cooling to $218 \mathrm{~K}$ three partially overlapping peaks are observed (Figure S4). In the reactions of triethoxysilane the acetate ${ }^{1} \mathrm{H}$ NMR signal splits into two distinct peaks at 1.91 and $2.09 \mathrm{ppm}$. The former corresponds to [TBA] [OAc], and the latter may be assigned to the silane-bound acetate, $\mathrm{R}_{3} \mathrm{SiOAc}$, the assignment of which is supported by comparison with separately prepared $\mathrm{EtO}_{3} \mathrm{SiOAc}^{42}$ Dynamic exchange between the two species was confirmed by EXSY NMR experiments (Figure S17).

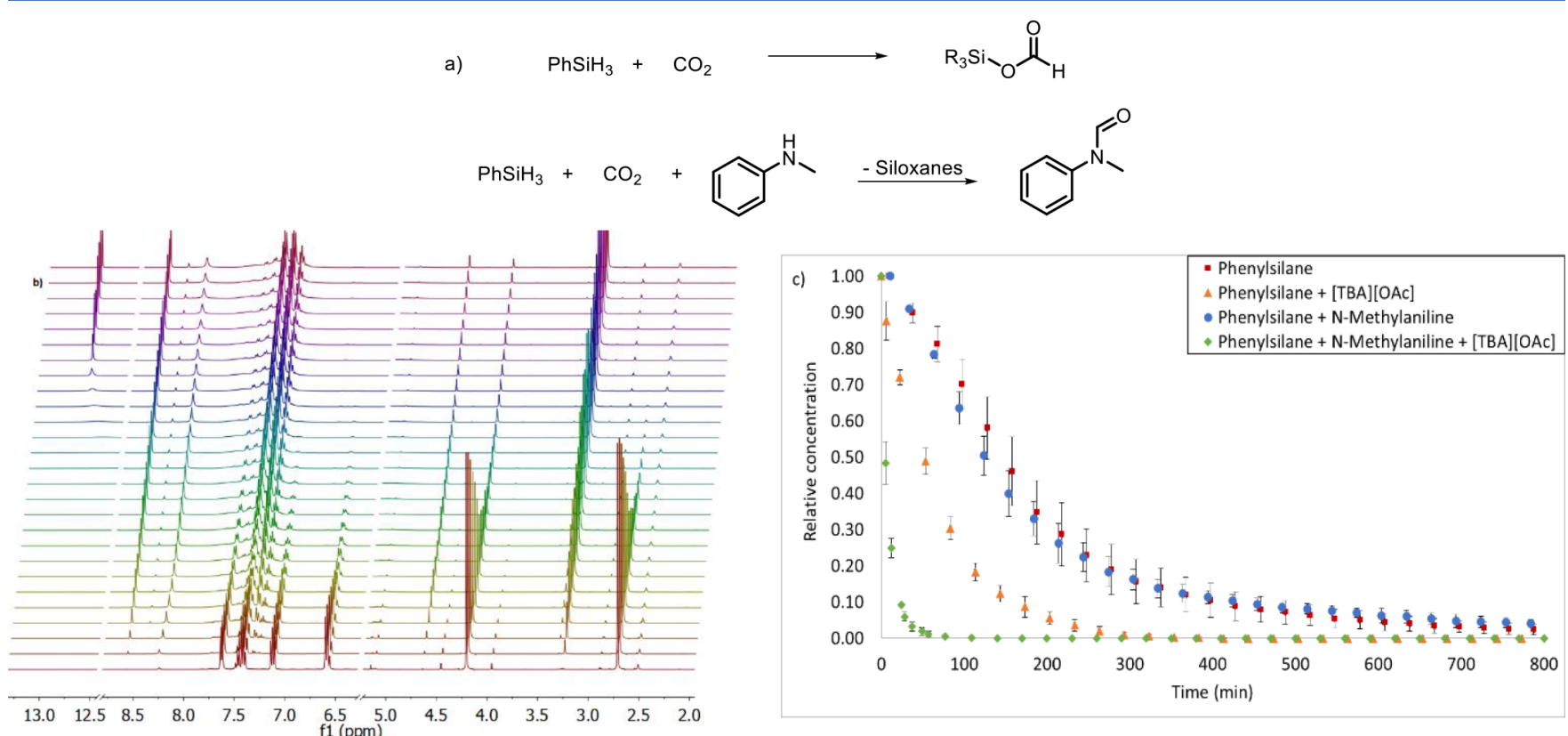

Figure 3. (a) Reaction of phenylsilane with $\mathrm{CO}_{2}$ in the presence and absence of $\mathrm{N}$-methylaniline. (b) Example of the ${ }^{1} \mathrm{H}$ NMR spectra of the $\mathrm{N}$ formylation of $\mathrm{N}$-methylaniline with $\mathrm{PhSiH}_{3}$ under $\mathrm{CO}_{2}(20 \mathrm{bar})$ over a period of $13 \mathrm{~h}$. For full spectra see Figure S28. (c) Consumption of phenylsilane over the course of the reactions (see inset for details). General reaction conditions: phenylsilane $(0.5 \mathrm{mmol}), \mathrm{N}$-methylaniline $(0.5$ mmol), DMSO-d $d_{6}(0.5 \mathrm{~mL}),[\mathrm{TBA}][\mathrm{OAc}](10 \mathrm{~mol} \%), \mathrm{CO}_{2}(20 \mathrm{bar}), 298 \mathrm{~K}$. 
Incorporation of the anion in the substituent exchange process was confirmed by the use of tetrabutylammonium formate $\left([\mathrm{TBA}]\left[\mathrm{HCO}_{2}\right]\right)$ instead of $[\mathrm{TBA}][\mathrm{OAc}]$. With $[\mathrm{TBA}]$ $\left[\mathrm{HCO}_{2}\right]$, upon addition of $\mathrm{CO}_{2}$, the peak corresponding to the formate anion disappears and only peaks attributable to formoxysilanes and the tetrabutylammonium cation are observed (Figures S21 and S22), confirming that the anion of the catalyst is involved in the exchange equilibrium. Proton exchange was also detected between the formyl - $\mathrm{CHO}$ protons and the formic acid $-\mathrm{OH}$ protons, which cannot be explained by a five-membered silicon-mediated transfer. However, such exchanges are known for reversible reductions of $\mathrm{CO}_{2}$ to formic acid with dihydrogen, ${ }^{43}$ indicating, at least in part, that formation of the formoxysilane is reversible: i.e., the hydrosilane and $\mathrm{CO}_{2}$ can re-form.

Finally, $N$-methylaniline was added to the reaction mixture and the consumption of phenylsilane (Figure 3 ) as well as the formation of $\mathrm{N}$-methylformanilide was monitored. In the absence of the [TBA][OAc] catalyst, phenylsilane was consumed at the same rate irrespective of whether $\mathrm{N}$ methylaniline is present or not. In addition, $N$-methylformanilide forms at a rate comparable to that of formoxysilane. The rate of phenylsilane consumption in the presence of the [TBA] [OAc] catalyst is considerably faster in the presence of $\mathrm{N}$-methylaniline (in comparison to the reaction without $\mathrm{N}$ methylaniline). The phenylsilane was completely consumed within $1 \mathrm{~h}$, in contrast to $6 \mathrm{~h}$ in the absence of $N$-methylaniline. Considering that formoxysilane formation was identified as the rate-determining step of pathway $1,{ }^{34}$ the absence of any intermediates is as expected. The equivalent $\mathrm{CO}_{2}$ reduction rates without the $[\mathrm{TBA}][\mathrm{OAc}]$ catalyst concur with DFT calculations that pathway 1 is the preferred $\mathrm{N}$-formylation route for $\mathrm{N}$-methylaniline in the absence of a catalyst. However, results with $[\mathrm{TBA}][\mathrm{OAc}]$ demonstrate that $N$ methylaniline provides an alternative, much faster pathway for $\mathrm{CO}_{2}$ reduction. Similar observations were made when triethoxysilane was employed as the reducing agent (Figures S11 and S31).

Overall, the reduction of $\mathrm{CO}_{2}$ with hydrosilanes results in a mixture of formoxysilanes with continuous substituent exchange around the silicon center. An off-cycle species, $\mathrm{R}_{3} \mathrm{SiOAc}$, forms during the reaction, resulting in the partial transformation of the catalyst to $[\mathrm{TBA}]\left[\mathrm{HCO}_{2}\right]$. Formic acid and various siloxanes are the main reaction side products, with the formation of bis(silylacetals) and methoxysilane in less than $2 \%$ yield. The formoxysilanes formed react with amines to form the formamide products. ${ }^{33}$ However, pathway 1 is only accessible for $\mathrm{N}$-methylaniline in the absence of a catalyst, as proposed by DFT calculations. ${ }^{34}$ Although [TBA][OAc] can activate hydrosilanes for direct $\mathrm{CO}_{2}$ reduction, $\mathrm{N}$-formylation of amines proceeds along a different, much faster pathway in the presence of this catalyst.

Pathway 2 and Role of the Amine. Pathway 2 was proposed on the basis of computational studies and the observation of the formoxysilane intermediate. ${ }^{35,36}$ In contrast to pathway 1 , the catalyst acts to stabilize the formation of a carbamate salt formed from the reaction of the amine with $\mathrm{CO}_{2}$, rather than activate the hydrosilane. The reaction of amines with $\mathrm{CO}_{2}$ to form carbamate salts is well established and is used on industrial scale to scrub $\mathrm{CO}_{2}$ from various gas streams. ${ }^{44}$ However, not all amines form stable carbamate salts, including $\mathrm{N}$-methylaniline. Base catalysts help to stabilize the salt, which then activates the hydrosilane in a manner similar to that proposed in pathway 1 (Scheme 5). In addition, a base catalyst can accelerate the subsequent reaction between the

Scheme 5. Pathway 2 for the $\mathrm{N}$-formylation of Amines: (a) Pathway 2 Reaction Scheme and (b) Proposed Mechanistic Cycle for the Rate-Determining $\mathrm{CO}_{2}$ Reduction Step ${ }^{35}$

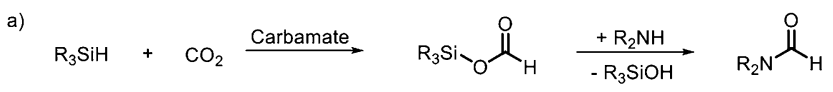

b)

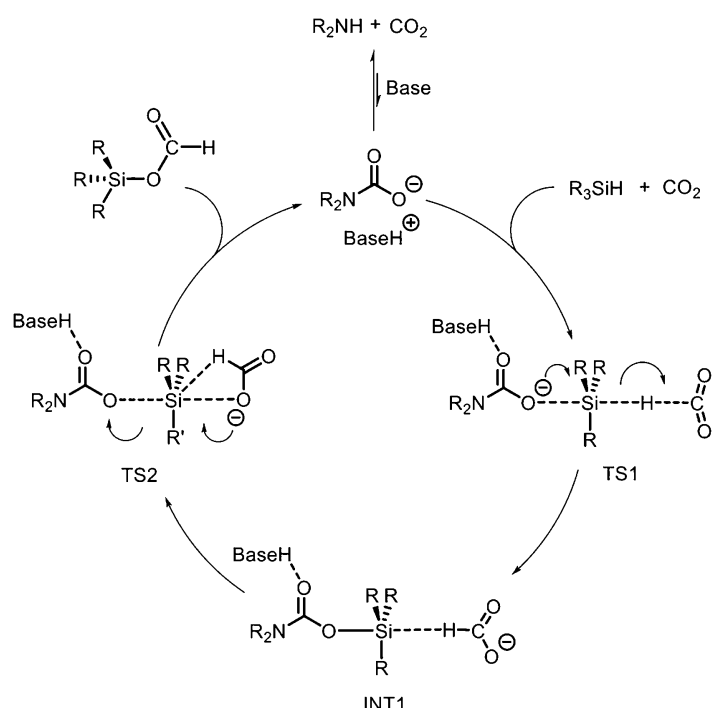

amine and the formed formoxysilane. ${ }^{35}$ Interestingly, all of the nucleophilic catalysts, including $[\mathrm{TBA}][\mathrm{OAc}]{ }^{23}$ fluorides, ${ }^{26}$ carbonates, ${ }^{24}$ and NHCs, ${ }^{6,16-18,45}$ are also basic. Furthermore, non-nucleophilic bases such as $\mathrm{TBD}^{27,28}$ and guanidines ${ }^{19}$ catalyze the $\mathrm{N}$-formylation reaction. A general base-catalyzed reaction mechanism would thus encompass the majority of organic and salt catalysts.

Kinetic studies of $N$-methylaniline formylation with phenylsilane and the $[\mathrm{TBA}][\mathrm{OAc}]$ catalyst reveal that the amine influences the rate of $\mathrm{CO}_{2}$ reduction with hydrosilanes (Figure 3 ). In addition, the $\mathrm{N}$-methylformanilide product forms at the same rate as the phenylsilane is consumed, and no intermediates were detected. The only noticeable changes in the NMR spectra during the course of the reaction are a broadening of the $-\mathrm{NH}$ signal of the $\mathrm{N}$-methylaniline and loss of its coupling to the methyl group upon addition of $\mathrm{CO}_{2}$, indicating partial formation of a carbamate salt. However, a peak corresponding to the carbamate carbon was not detected by ${ }^{13} \mathrm{C}$ NMR spectroscopy, which supports the transient nature of such a salt even in the presence of a base catalyst. Pathways 2 and 3 were both proposed to proceed by the formation of a carbamate salt, with different intermediates derived from the carbamate salt proposed for each route. ${ }^{19,35,36}$ Identifying the intermediate, either a formoxysilane or a silylcarbamate, that leads to the product is key for distinguishing between pathways 2 and 3. However, the only compounds identified were phenylsilane, $\mathrm{N}$-methylaniline, $\mathrm{N}$-methylformanilide, formic acid, and some minor side products, i.e. bis(silylacetals) and methoxysilane. The presence of formic acid slightly favors pathway 2 over pathway 3 , as the intermediate in the formation of formic acid is formoxysilane. ${ }^{46}$ However, the side products and byproducts observed during the formation of a silylcarbamate have not been previously reported and, as 


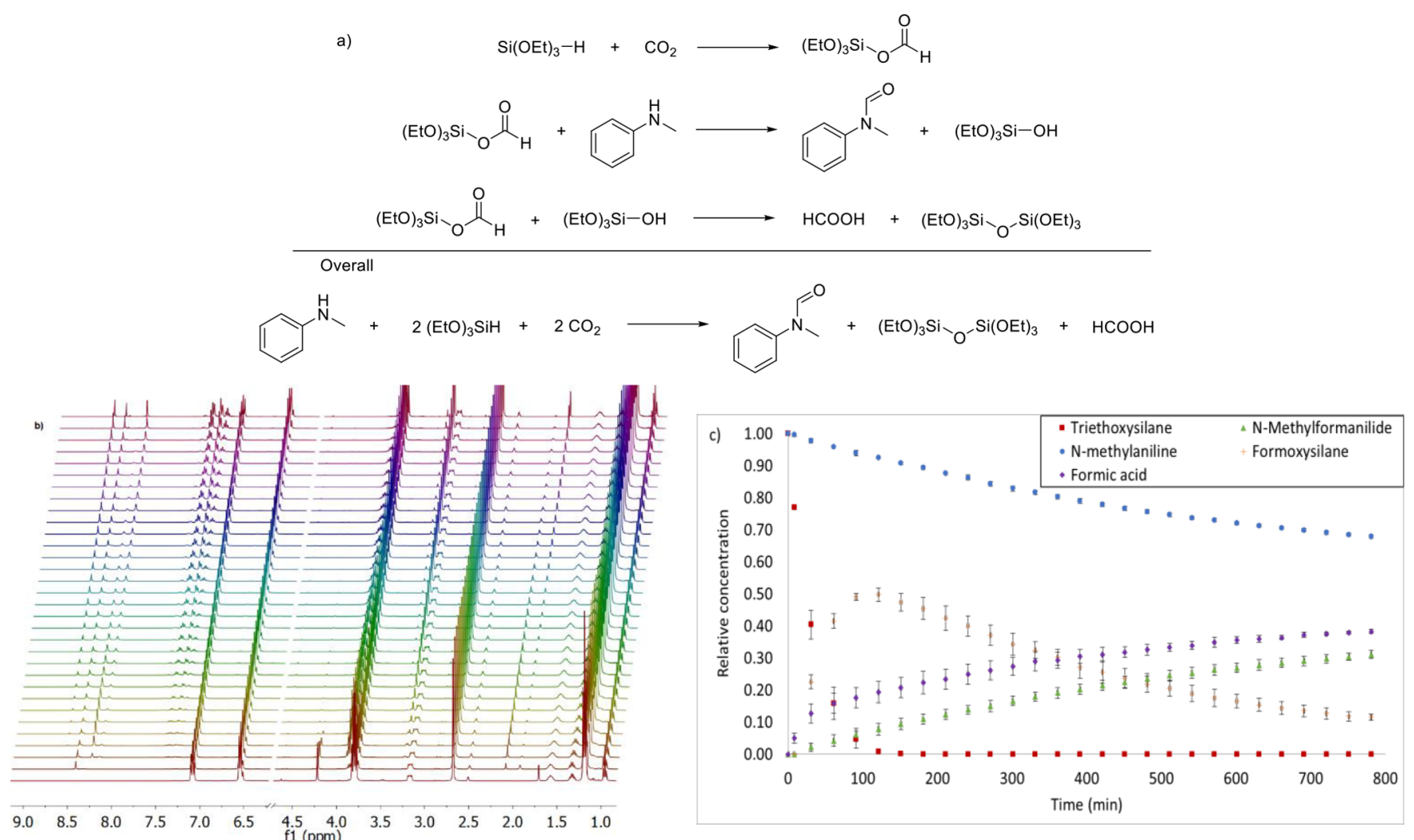

Figure 4. (a) N-formylation of $\mathrm{N}$-methylaniline with $\mathrm{CO}_{2}$ and triethoxysilane and its side reactions and byproducts. (b) ${ }^{1} \mathrm{H}$ NMR spectra of $\mathrm{N}$ methylaniline $\mathrm{N}$-formylation with $\mathrm{EtO}_{3} \mathrm{SiH}$ under $\mathrm{CO}_{2}(20 \mathrm{bar})$ over a period of $13 \mathrm{~h}$. For full spectra see Figure $\mathrm{S} 30$. (c) Kinetic curves for the formylation of $\mathrm{N}$-methylaniline using triethoxysilane. Reaction conditions: triethoxysilane $(0.5 \mathrm{mmol}), \mathrm{N}$-methylaniline $(0.5 \mathrm{mmol}), \mathrm{DMSO}-d_{6}(0.5$ $\mathrm{mL}),[\mathrm{TBA}][\mathrm{OAc}](10 \mathrm{~mol} \%), \mathrm{CO}_{2}(20 \mathrm{bar}), 298 \mathrm{~K}$.

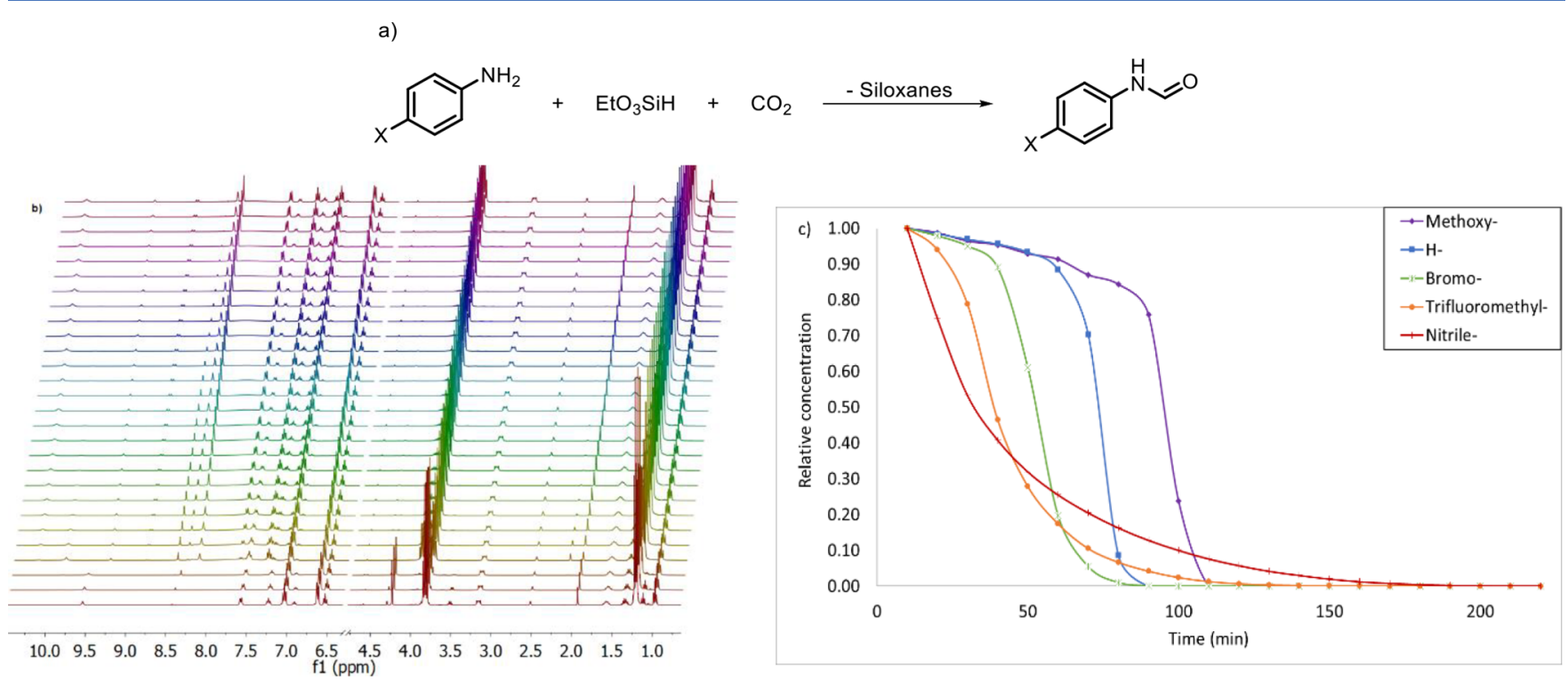

Figure 5. (a) Reaction of para-substituted anilines with $\mathrm{CO}_{2}$ and triethoxysilane. (b) Example of the ${ }^{1} \mathrm{H}$ NMR spectra of the N-formylation of aniline with $\mathrm{EtO}_{3} \mathrm{SiH}$ under $\mathrm{CO}_{2}(20 \mathrm{bar})$ over a period of $13 \mathrm{~h}$. For full spectra see Figure S51. (c) Consumption of triethoxysilane in the Nformylation reactions of methoxyaniline, aniline, bromoaniline, trifluoromethylaniline, and 4-aminobenzonitrile. Reaction conditions: triethoxysilane $(0.6 \mathrm{mmol})$, aniline $(0.5 \mathrm{mmol}), \mathrm{DMSO}-d_{6}(0.5 \mathrm{~mL}),[\mathrm{TBA}][\mathrm{OAc}](10 \mathrm{~mol} \%), \mathrm{CO}_{2}(20 \mathrm{bar}), 298 \mathrm{~K}$.

such, the presence of formic acid does not distinguish between the two pathways.

Ex situ reaction of the formoxysilane $\mathrm{EtO}_{3} \mathrm{SiOCHO}$ with $\mathrm{N}$ methylaniline to give $\mathrm{N}$-methylformamide has been reported. ${ }^{33}$ Monitoring the reaction of $\mathrm{N}$-formylation with triethoxysilane revealed the formation of at least three different formoxysilanes, identified by the appropriate - CHO signals in the ${ }^{1} \mathrm{H}$, ${ }^{13} \mathrm{C}$, and ${ }^{29} \mathrm{Si}$ NMR spectra (Figures S33-S35) and facilitated by comparison to spectra recorded for $\mathrm{CO}_{2}$ reduction reactions in the absence of $\mathrm{N}$-methylaniline. Two of the three 
formoxysilanes were gradually consumed during the reaction at $298 \mathrm{~K}$, whereas the remaining formoxysilane reacted rapidly only after heating to $378 \mathrm{~K}$. Simultaneous $\mathrm{N}$-formanilide formation was observed, further supporting pathway 2 (Figure 4). However, when all of the starting triethoxysilane was consumed, it became apparent that 2 equiv of formoxysilane is required to obtain $\mathrm{N}$-methylformanilide, as the formoxysilanes were consumed at twice the rate at which the $N$ methylformanilide was formed. As formic acid forms at an equivalent rate to the $N$-methylformanilide and no silanol byproduct was observed, it seems likely that the silanol produced rapidly reacts with formoxysilane to generate various siloxanes and formic acid, as observed in the earlier reactions.

The presence of $\mathrm{EtO}_{3} \mathrm{SiOSiOEt}_{3}$ as well as higher weight siloxanes was confirmed by GC-MS at the end of the reaction. Excess formic acid, in comparison to $\mathrm{N}$-methylformanilide, may be attributed to the rapid initial reaction of formoxysilane with trace water present in the solvent. Overall, 2 equiv of hydrosilane and $\mathrm{CO}_{2}$ is required to produce 1 equiv of $\mathrm{N}$ methylformanilide, with the simultaneous formation of formic acid and a siloxane (Figure 4a).

The formation of formoxysilanes and their reaction with $\mathrm{N}$ methylaniline confirm that the $N$-methylformanilide is formed via pathway 2 in the presence of the [TBA] [OAc] catalyst. In addition, pathway 2 proceeds via a similar five-membered hypervalent silicon TS to pathway 1 (Schemes 2 and 5), ${ }^{35}$ which allows for exchange around the silicon center, substantiated by the multiple formoxysilanes observed rather than $\mathrm{EtO}_{3} \mathrm{SiOCHO}$ alone. The substituent exchange process was confirmed by EXSY experiments (Figure S36). Interestingly, exchange between the acetate anion (observed at 1.93 ppm) and silane-bound acetate (observed at $2.09 \mathrm{ppm}$ ) also takes place, indicating that pathway 1 may compete with pathway 2 during $\mathrm{N}$-methylaniline formylation or that the [TBA][OAc] catalyst is, at least in part, transformed to $[\mathrm{TBA}]\left[\mathrm{HCO}_{2}\right]$ or deactivated following reaction of the acetate with the silicon center.

To ascertain the role of the amine and the related carbamate salt on the reaction, a series of para-substituted anilines were $\mathrm{N}$-formylated under the standardized reaction conditions using triethoxysilane. The progress of the $\mathrm{N}$-formylation reactions was monitored by ${ }^{1} \mathrm{H}$ NMR spectroscopy and the rate of hydrosilane consumption recorded (Figure 5). Both the reaction rate and the entire reaction kinetics demonstrated a strong dependence on the nature of the amine. As the basicity of the amine and the stability of the carbamate salt increases, an induction period for the $\mathrm{N}$-formylation reaction is observed, followed by a sudden and rapid depletion of the triethoxysilane and amine, but without the formation of the product (Figures S52 and S56). Instead, an intermediate presumed to be silylcarbamate, ${ }^{19}$ from which the product forms, was observed (vide infra). Formoxysilanes were also detected, and as the basicity of the amine increases, they are consumed more rapidly. Only 4-aminobenzonitrile and to some extent 4trifluoromethylaniline undergo direct observable conversion of formoxysilanes to their respective $\mathrm{N}$-formylated products (Figures S40 and S44). In all other cases, formation of a new silylcarbamate intermediate dominates the reaction. Apparently, as the basicity of the amine increases, pathway 2 is gradually suppressed and pathway 3 becomes the dominate reaction pathway.

Thus, $N$-methylaniline formylation proceeds via pathway 2, as previously proposed by DFT calculations. ${ }^{35,36} \mathrm{~A}$ mixture of formoxysilanes with different reactivities is formed, which then react with $\mathrm{N}$-methylaniline to form the desired product. However, 2 equiv of $\mathrm{Si}-\mathrm{H}$ and $\mathrm{CO}_{2}$ is required for the $\mathrm{N}$ formylation reaction due to simultaneous formation of a siloxane and formic acid. Nevertheless, the reaction pathway is not universal for all amines but appears to operate only for amines of low basicity, which do not form stable carbamate salts. An alternative reaction pathway with an additional intermediate is responsible for the $\mathrm{N}$-formylation of more basic amines. The transition from pathway 2 to pathway 3 does not appear immediately, but rather as a gradual transition, where both pathways compete with each other with amines of intermediate basicity.

Pathway 3. Pathway 3, involving a silylcarbamate intermediate, was proposed from the $\mathrm{N}$-formylation of morpholine. ${ }^{19,30}$ Morpholine, like some of the other anilines studied, forms a stable carbamate salt even in the absence of a base. Moreover, stabilization of the carbamate salt was demonstrated as nonessential and potentially degradatory for the $\mathrm{N}$-formylation of morpholine. ${ }^{19}$ Nevertheless, base catalysts including guanidines, ${ }^{19} \mathrm{TBD},{ }^{27,28} \mathrm{Cs}_{2} \mathrm{CO}_{3}{ }^{24}$ and carboxylates $^{22}$ catalyze the $\mathrm{N}$-formylation of morpholine. However, the role of the base in pathway 3 remains unclear. Indeed, little is known about pathway 3, including the mechanism by which the silylcarbamate is formed and its subsequent transformation into the $\mathrm{N}$-formylated product. Two possibilities were proposed for its transformation to the product (Scheme 6). ${ }^{19}$ One is direct, and the other includes

Scheme 6. Proposed Transformations of Silylcarbamate to $\mathrm{N}$-formylated Compounds along Pathway $3^{a}$

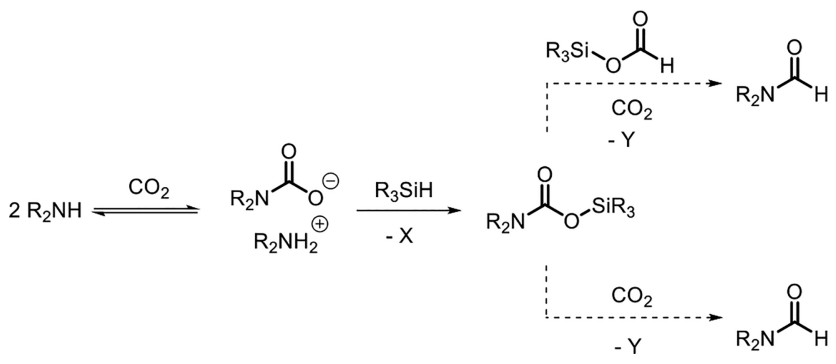

${ }^{a} \mathrm{X}$ and $\mathrm{Y}$ represent previously unreported reaction side products. The scheme is adapted from ref 19 .

the other known formoxysilane intermediate. In both cases, $\mathrm{CO}_{2}$ was required for the transformation to proceed in the presence of the tetramethylguanidine catalyst. ${ }^{19}$ Understanding the silylcarbamate intermediate and its formation and reactivity as well as the formoxysilane role and the reaction delay is essential to complete pathway 3 . For this purpose, the reaction of benzylamine with triethoxysilane was studied, with each step of the reaction analyzed.

The reaction of benzylamine with $\mathrm{CO}_{2}$ and triethoxysilane may be divided into three phases (Figure 6). First, the induction period: upon addition of $\mathrm{CO}_{2}$ benzylamine is directly converted to benzylcarbamic acid, rather than the previously proposed benzylcarbamate, but then remains essentially unchanged for the next $100 \mathrm{~min}$ of the reaction. During this period, only $8 \%$ of the triethoxysilane reacts to form formic acid. Notably, traces of ethanol are also detected. The second phase comprises an extremely rapid reaction between triethoxysilane and benzylcarbamic acid, and within $10 \mathrm{~min}$, all of the hydrosilane and $65 \%$ of benzylcarbamic acid 
a)

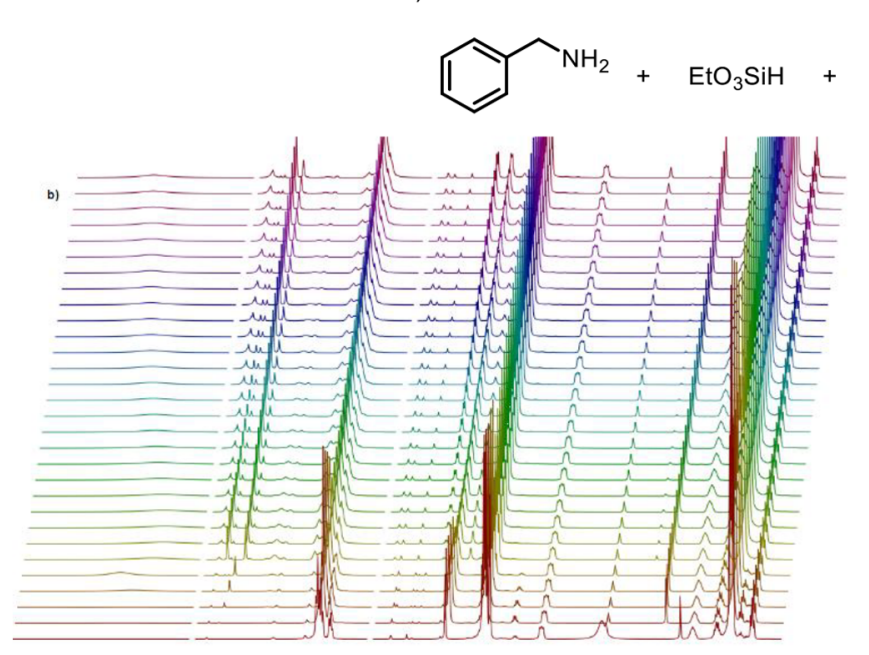

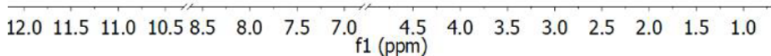

$\mathrm{CO}_{2} \stackrel{\text { - Siloxanes }}{\longrightarrow}$

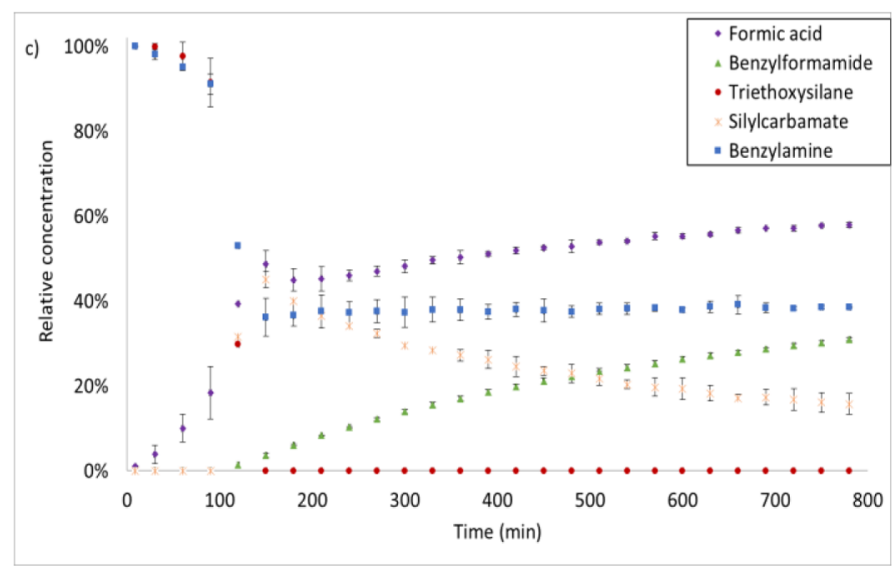

Figure 6. (a) N-formylation of benzylamine with triethoxysilane. (b) ${ }^{1} \mathrm{H}$ NMR spectra of benzylamine $\mathrm{N}$-formylation with $\mathrm{EtO}_{3} \mathrm{SiH}_{\mathrm{inder}} \mathrm{CO}_{2}(20$ bar) over a period of $13 \mathrm{~h}$. For full spectra see Figure S58. (c) Kinetic curves for the $\mathrm{N}$-formylation of benzylamine with triethoxysilane and $\mathrm{CO}_{2}$. Reaction conditions: triethoxysilane $(0.5 \mathrm{mmol})$, benzylamine $(0.5 \mathrm{mmol}), \mathrm{DMSO}-d_{6}(0.5 \mathrm{~mL}),[\mathrm{TBA}][\mathrm{OAc}](10 \mathrm{~mol} \%), \mathrm{CO}_{2}(20 \mathrm{bar}), 298 \mathrm{~K}$.

Scheme 7. Proposed Reactions Involved in the Water-Induced Delay to the N-formylation Reaction: (a) Proposed Series of Reactions Responsible for Benzylamine N-Formylation Reaction Delay and (b) Overall Observable Reaction

a)

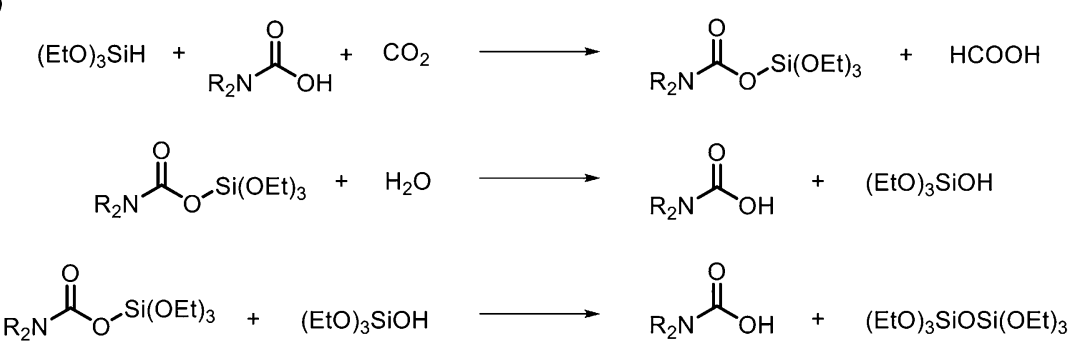

b) Overall

$2 \mathrm{EtO}_{3} \mathrm{SiH}+2 \mathrm{CO}_{2}+\mathrm{H}_{2} \mathrm{O}$

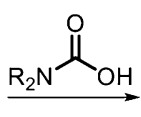

$(\mathrm{EtO})_{3} \mathrm{SiOSi}(\mathrm{OEt})_{3}+2 \mathrm{HCOOH}$

are consumed. However, the $\mathrm{N}$-formylated product is not observed and, instead, an intermediate identified as silylcarbamate $19,30,47,48$ appears, supporting the proposed pathway 3 . Simultaneously, a large increase in the quantity of formic acid is observed. The third stage of the reaction involves the gradual conversion of the silylcarbamate to the $\mathrm{N}$-benzylformamide product.

The initial reaction kinetics resemble product-catalyzed reactions, but upon addition of $20 \mathrm{~mol} \%$ of benzylformanilide to the reaction mixture no changes were observed (Figures S72 and S73). Addition of formic acid slightly accelerates the reaction (Figures S74 and S75). However, the acceleration is insufficient to explain the observed "step" change during Nformylation of benzylamine. One way in which formic acid can form in the reaction is from the hydrolysis of formoxysilane with trace water. ${ }^{38,46}$ Hence, we hypothesized that water causes a reaction delay, which is the opposite of product-catalyzed reactions with a similar kinetic profile. Indeed, addition of trace amounts of water increases the induction time from 100 to 300 min, slightly larger quantities increase the time to almost 400 $\mathrm{min}$, and further increases result in the slow, but complete, transformation of triethoxysilane to formic acid (Figures S76-
$\mathrm{S} 81)$. In the reaction with excess water, $\mathrm{N}$-formylation was not observed and the reaction stopped after depletion of the triethoxysilane. Large quantities of water also prevent the $\mathrm{N}$ formylation reaction when phenylsilane is used as the reductant. However, trace water and even quantities as large as $10 \mathrm{~mol} \%$ do not affect the reaction kinetics ${ }^{19}$ as in the case of triethoxysilane. In the presence of the catalyst, phenylsilane rapidly reacts with water, removing it prior to reaction with $\mathrm{CO}_{2} \cdot{ }^{49,50}$ As a result, trace water only decreases the initial quantity of phenylsilane in the reaction rather than causing a reaction delay.

A second way in which formic acid can potentially form is from the reaction of carbamic acid with the hydrosilane and $\mathrm{CO}_{2}$, resulting in the simultaneous formation of the silylcarbamate. This reaction is actually observed in the second phase of the $\mathrm{N}$-formylation reaction, where silylcarbamate forms along with large quantities of formic acid. However, in the presence of water silylcarbamates are readily hydrolyzed back to carbamic acids and silanols, ${ }^{51}$ which can react further with silylcarbamates to form the corresponding carbamic acids and $\mathrm{EtO}_{3} \mathrm{SiOSiOEt}_{3}$ (Scheme 7). ${ }^{52}$ 
Considering that carbamic acids are required for the reaction delay, it appears that the reaction of carbamic acid with hydrosilane and $\mathrm{CO}_{2}$ followed by hydrolysis of the resulting silylcarbamate is responsible for the induction period observed during benzylamine $\mathrm{N}$-formylation with triethoxysilane. Thus, when all water and silanols are consumed, the desired $\mathrm{N}$ formylation reaction can proceed, which is characterized by rapid consumption of triethoxysilane and benzylcarbamic acid and the concomitant formation of formoxysilanes and silylcarbamates.

The reactions are accompanied by characteristic substituent exchange around the silicon center, identified by the presence of ethanol in the initial phases of the reaction and confirmed by EXSY NMR experiments as well as the detection of tetraethoxysilane (Figure S64). Hence, five-membered TSs are expected for pathway 3 en route to silylcarbamate similar to those for pathway 2 toward formoxysilanes. In the presence of an amine, two such TSs and one high-energy intermediate were proposed by DFT calculations during formoxysilane formation (Scheme 8$).{ }^{35}$ Moreover, the intermediate strongly

Scheme 8. Calculated Transition States and Intermediates along Pathway 2 for $\mathrm{CO}_{2}$ Reduction with Hydrosilanes ${ }^{35}$

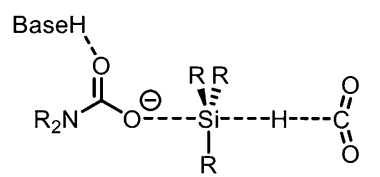

TS1

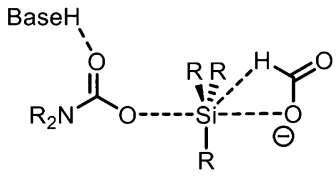

TS2
BaseH<smiles>[R16]C(OC)O[Si]([R])([R])[CH]C(=O)[O-]</smiles>

INT1

resembles the silylcarbamate observed during the $\mathrm{N}$ formylation of benzylamine. The only difference is incomplete elimination of formate/formic acid from the intermediate. However, formic acid is also observed during the $\mathrm{N}$ formylation of benzylamine. Hence, it appears that stabilization of the carbamate $\left(\mathrm{R}_{2} \mathrm{NCOO}^{-}\right)$with basic amines results in the complete transformation of this calculated intermediate to the experimentally observed silylcarbamate and formic acid. The silylcarbamates then react with formic acid to form formoxysilane(s). Hence, almost the same mechanism can be proposed for pathway 3 as for pathway 2 (Scheme 9). The observed difference between pathways 2 and 3 is dependent on the relative stabilities of silylcarbamates and formoxysilanes, which defines the major intermediate detected in solution. For benzylamine and morpholine it is the silylcarbamate. A mixture of silylcarbamates and formoxysilanes is formed with parasubstituted anilines. Finally, in the case of $N$-methylaniline only formoxysilanes are detected. Nevertheless, the pathways do not seem to substantially differ, at least during the reduction of $\mathrm{CO}_{2}$, and only the most stable intermediate along the $\mathrm{N}$ formylation pathway varies.

In the final stage of the reaction, benzylformamide gradually forms from the reaction of benzylamine with formoxysilane. However, the rate of the reaction is dependent on the stability of the silylcarbamate, which hinders formoxysilane formation. Overall, benzylamine $\mathrm{N}$-formylation with triethoxysilane
Scheme 9. Pathway 3 for the N-Formylation of Amines: (a) Pathway 3 Reaction Scheme and (b) Proposed Mechanistic Cycle for the Rate-Determining $\mathrm{CO}_{2}$ Reduction Step
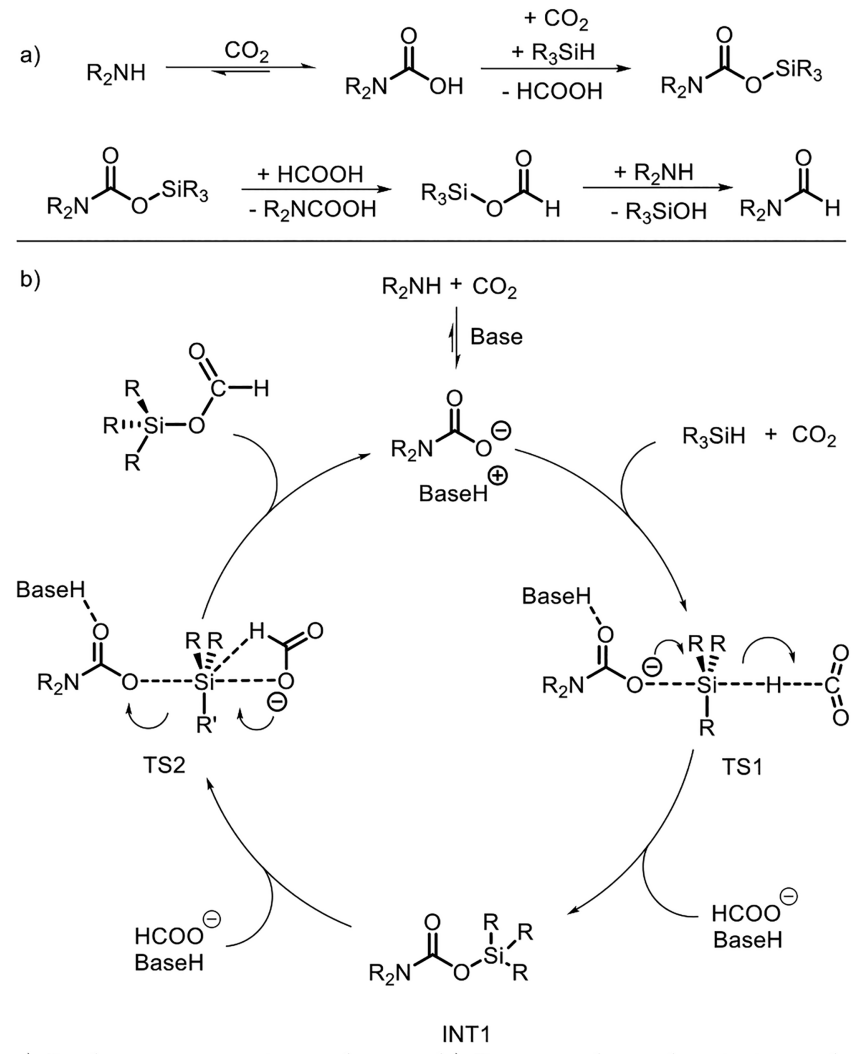

proceeds at a rate comparable to that of the $\mathrm{N}$-formylation of $\mathrm{N}$-methylaniline. Nevertheless, with phenylsilane, $\mathrm{N}$ formylation of benzylamine is $\sim 3.3$ times faster (Figures S84 and S85). The effect of the hydrosilane on the reaction rate is usually assigned to the $\mathrm{S}_{\mathrm{N}} 2$-type TS formed during reduction of $\mathrm{CO}_{2}$ and, hence, steric hindrance around the silicon center. $^{26}$ However, phenylsilane also has three $\mathrm{Si}-\mathrm{H}$ bonds, which can act as a hydride source, whereas triethoxysilane only has one. In effect, with phenylsilane an excess of reducing agent is normally used. Similarly, excess triethoxysilane results in the complete $\mathrm{N}$-formylation of benzylamine within $4 \mathrm{~h}$ in comparison to incomplete reaction after $13 \mathrm{~h}$ with only 1 equiv of the hydrosilane (Figures S82 and S83). Five equivalents of triethoxysilane was used for the experiment, rather than three, in order to compensate for the formation of formoxysilane. Surprisingly, the excess triethoxysilane only slightly decreases the initial reaction delay to $60 \mathrm{~min}$ and does not affect the rate of silylcarbamate formation. However, the excess hydrosilane strongly affects the rate of the transformation of the silylcarbamate to the $\mathrm{N}$-formylated product.

Direct conversion of silylcarbamates to the product has been proposed. ${ }^{19,30}$ In addition, silylcarbamate cleavage with chlorosilanes to siloxanes and isocyanates is known. ${ }^{51}$ The formation of siloxanes also appears as the final reaction byproduct of the $\mathrm{N}$-formylation reaction, which suggests that direct reduction of silylcarbamates with excess hydrosilane to $\mathrm{N}$-formylated compounds and siloxanes is possible. In the absence of excess hydrosilane the silylcarbamate is gradually converted to formoxysilane, leading to the slow formaton of the $\mathrm{N}$-formylated product. However, in the presence of excess 
Scheme 10. Proposed Pathway $3^{\prime}$ for the $N$-Formylation of Amines

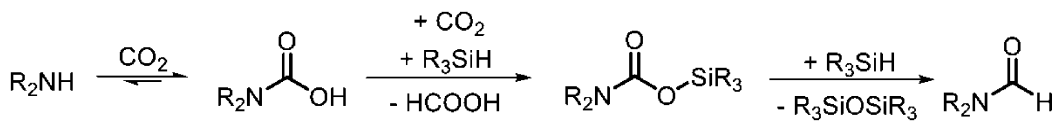

Scheme 11. Overview of N-formylation Reaction Pathways in Relation to the Conditions ${ }^{a}$

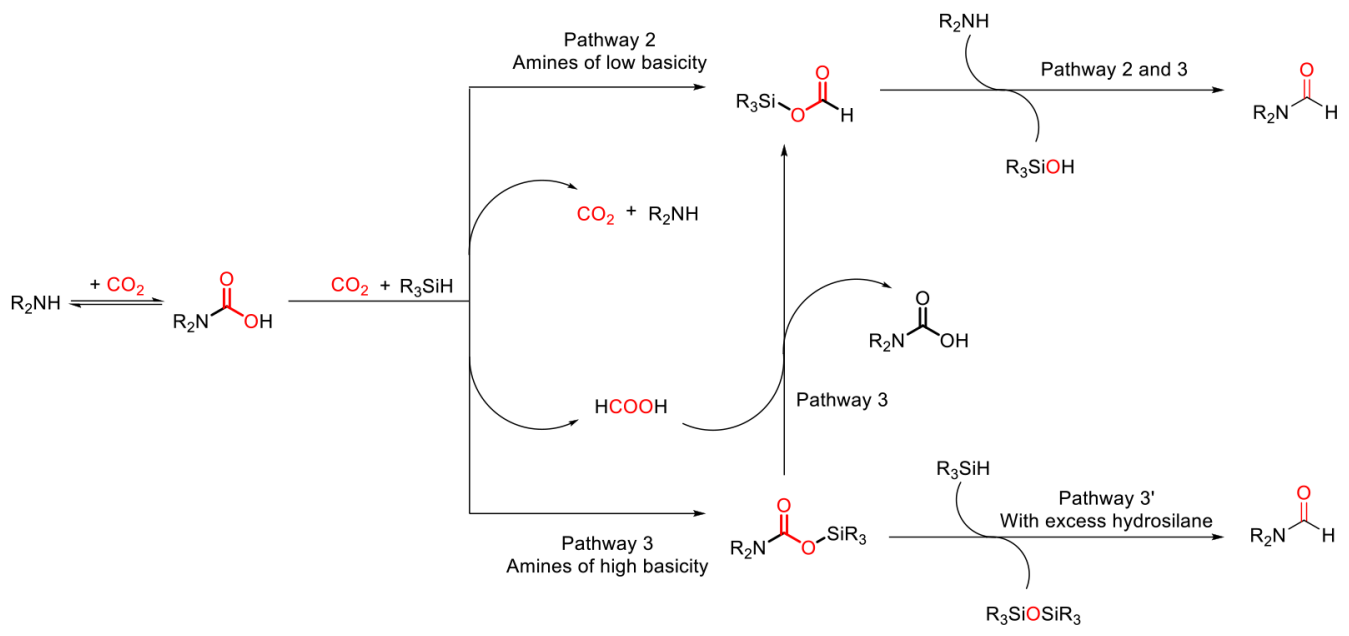

${ }^{a}$ Formoxysilane and silylcarbamate side reactions with silanols are not shown for clarity.

hydrosilane, the silylcarbamate is directly reduced to the formamide, which corresponds to pathway 3' (Scheme 10).

Thus, pathways 2 and 3 share the same mechanism for the $\mathrm{CO}_{2}$ reduction step but differ according to the relative stabilities of the silylcarbamate and formoxysilane intermediates, which define the major intermediate observed in solution. Due to the low stability of the carbamate linkage $\left(\mathrm{NCOO}^{-}\right)$ with $\mathrm{N}$-methylaniline, no silylcarbamates are observed and only formoxysilanes are detected. However, as the stability of carbamate increases, silylcarbamate formation becomes gradually favored until it becomes the dominant species in solution. A mixture of silylcarbamates and formoxysilanes is observed between the two extreme cases. The $\mathrm{N}$-formylated product forms by gradual conversion of silylcarbamate to formoxysilane, which then reacts with the amine to form the desired product. Formate or formic acid is required for silylcarbamate transformation to formoxysilane rather than $\mathrm{CO}_{2}$ as previously proposed. ${ }^{19}$ Nevertheless, in the presence of excess hydrosilane the silylcarbamate can be directly reduced to the final $\mathrm{N}$ formylated product without the need for formoxysilane formation (Scheme 11).

\section{CONCLUSIONS}

Three possible pathways have been proposed for the $\mathrm{N}$ formylation of amines with $\mathrm{CO}_{2}$ and hydrosilanes. Pathway 1, based on the direct insertion of $\mathrm{CO}_{2}$ into the hydrosilane, was demonstrated to only operate for the $\mathrm{N}$-formylation of lowbasicity amines in the absence of a catalyst. However, in the presence of a base catalyst, $\mathrm{N}$-formylation of $\mathrm{N}$-methylaniline follows pathway 2, where base-stabilized carbamate salts activate the hydrosilane prior to $\mathrm{CO}_{2}$ insertion. Some evidence suggests that direct hydrosilane activation with nucleophilic base catalysts simultaneously takes place. However, as the basicity of the amine and the related carbamate stability increases, pathway 1 is overshadowed by pathway 2 , which in turn is overtaken by pathway 3 in the case of highly basic amines such as morpholine and benzylamine.
Pathway 3 appears to follow a $\mathrm{CO}_{2}$ reduction mechanism similar to that of pathway 2, but with increased stability of the carbamate linkage $\left(\mathrm{NCOO}^{-}\right)$. As a result, stable silylcarbamates are observed en route to formoxysilanes and are detected in solution instead (or together) with formoxysilanes. The final $\mathrm{N}$-formylated compounds form either from the reaction of the amine with formoxysilane or by the direct reduction of the silylcarbamates with excess hydrosilane (pathway $3^{\prime}$ ). Consequently, the $\mathrm{N}$-formylation pathway is dependent on the amine and the quantity of hydrosilane present. It is likely that the substrate dependence might also explain the discrepancy in proposed pathways toward $\mathrm{N}$ methylamines and aminals, which in the first step also originate from the reduction of $\mathrm{CO}_{2}$ to formoxysilanes but may vary according to the stability of the silylcarbamate.

For all $\mathrm{CO}_{2}$ reduction reactions with hydrosilanes, substituent exchange is observed around the silicon center of the hydrosilane supporting the formation of a five-membered hypervalent silicon species during the reaction, either as an intermediate or, more likely, as an $\mathrm{S}_{\mathrm{N}}$ 2-type transition state. ${ }^{35}$ Silanols, the primary reaction byproducts, further react with the formoxysilane intermediates, resulting in formic acid and siloxanes, and an amine to hydrosilane ( $\mathrm{Si}-\mathrm{H}$ bond) ratio of at least $1: 2$ is required. The ratio needed increases in the presence of water, which hydrolyzes the formoxysilanes to silanols, siloxanes, and formic acid. In the case of silylcarbamate, water induces a reaction delay, as the silylcarbamate intermediate undergoes hydrolysis back to the starting carbamate and silanols, which further hinder the reaction. However, as phenylsilane is the most commonly used hydrosilane, the amine to $\mathrm{Si}-\mathrm{H}$ ratio is automatically augmented to $1: 3$, resulting in little significance of water-induced side reactions.

Finally, this study demonstrates that organic and salt $\mathrm{N}$ formylation catalysts act as bases rather than nucleophiles. A general base-catalyzed mechanism indicates that a large number of bases will be catalytically active for the reaction. It is our hope that these findings will facilitate the search for 
optimal base catalysts and the development of even more efficient $\mathrm{N}$-formylation reaction with $\mathrm{CO}_{2}$.

\section{ASSOCIATED CONTENT}

\section{S Supporting Information}

The Supporting Information is available free of charge on the ACS Publications website at DOI: 10.1021/acscatal.8b03274.

Experimental procedures and NMR spectra (PDF)

\section{AUTHOR INFORMATION}

\section{Corresponding Author}

*E-mail for P.J.D.: pjd@epfl.ch.

\section{ORCID}

Gabor Laurenczy: 0000-0002-4354-4521

Paul J. Dyson: 0000-0003-3117-3249

\section{Notes}

The authors declare no competing financial interest.

\section{ACKNOWLEDGMENTS}

We thank the EPFL and the Swiss Competence Center for Energy research (SCCER) for funding.

\section{REFERENCES}

(1) Li, Y.; Cui, X.; Dong, K.; Junge, K.; Beller, M. Utilization of CO ${ }_{2}$ as a C1 Building Block for Catalytic Methylation Reactions. ACS Catal. 2017, 7, 1077-1086.

(2) Tlili, A.; Blondiaux, E.; Frogneux, X.; Cantat, T. Reductive Functionalization of $\mathrm{CO} 2$ with Amines: An Entry to Formamide, Formamidine and Methylamine Derivatives. Green Chem. 2015, 17, 157-168.

(3) Liu, X.-F.; Li, X.-Y.; Qiao, C.; He, L.-N. Transition-Metal-Free Catalysis for the Reductive -Functionalization of $\mathrm{CO} 2$ with Amines. Synlett 2018, 29, 548-555.

(4) Klankermayer, J.; Wesselbaum, S.; Beydoun, K.; Leitner, W. Selective Catalytic Synthesis Using the Combination of Carbon Dioxide and Hydrogen: Catalytic Chess at the Interface of Energy and Chemistry. Angew. Chem., Int. Ed. 2016, 55, 7296-7343.

(5) Aresta, M. Carbon Dioxide as Chemical Feedstock, 1st ed.; WileyVCH: Weinheim, Germany, 2010.

(6) Jacquet, O.; Das Neves Gomes, C.; Ephritikhine, M.; Cantat, T. Recycling of Carbon and Silicon Wastes: Room Temperature Formylation of N-H Bonds Using Carbon Dioxide and Polymethylhydrosiloxane. J. Am. Chem. Soc. 2012, 134, 2934-2937.

(7) Nguyen, T. V. Q.; Yoo, W.-J.; Kobayashi, S. Effective Formylation of Amines with Carbon Dioxide and Diphenylsilane Catalyzed by Chelating Bis( $T z$ NHC) Rhodium Complexes. Angew. Chem., Int. Ed. 2015, 54, 9209-9212.

(8) Li, Y.; Fang, X.; Junge, K.; Beller, M. A General Catalytic Methylation of Amines Using Carbon Dioxide. Angew. Chem., Int. Ed. 2013, 52, 9568-9571.

(9) Morris, D. S.; Weetman, C.; Wennmacher, J. T. C.; Cokoja, M.; Drees, M.; Kühn, F. E.; Love, J. B. Reduction of Carbon Dioxide and Organic Carbonyls by Hydrosilanes Catalysed by the Perrhenate Anion. Catal. Sci. Technol. 2017, 7, 2838-2845.

(10) Wang, M.-Y.; Wang, N.; Liu, X.-F.; Qiao, C.; He, L.-N. Tungstate Catalysis: Pressure-Switched 2- and 6-Electron Reductive Functionalization of $\mathrm{CO}_{2}$ with Amines and Phenylsilane. Green Chem. 2018, 20, 1564-1570.

(11) Motokura, K.; Takahashi, N.; Kashiwame, D.; Yamaguchi, S.; Miyaji, A.; Baba, T. Copper-Diphosphine Complex Catalysts for NFormylation of Amines under 1 Atm of Carbon Dioxide with Polymethylhydrosiloxane. Catal. Sci. Technol. 2013, 3, 2392-2396.

(12) Zhang, S.; Mei, Q.; Liu, H.; Liu, H.; Zhang, Z.; Han, B. Copper-Catalyzed N-Formylation of Amines with $\mathrm{CO}_{2}$ under Ambient Conditions. RSC Adv. 2016, 6, 32370-32373.
(13) Jacquet, O.; Frogneux, X.; Das Neves Gomes, C.; Cantat, T. $\mathrm{CO} 2$ as a C1-Building Block for the Catalytic Methylation of Amines. Chem. Sci. 2013, 4, 2127-2131.

(14) Luo, R.; Lin, X.; Chen, Y.; Zhang, W.; Zhou, X.; Ji, H. Cooperative Catalytic Activation of $\mathrm{Si}-\mathrm{H}$ Bonds: $\mathrm{CO}_{2}$-Based Synthesis of Formamides from Amines and Hydrosilanes under Mild Conditions. ChemSusChem 2017, 10, 1224-1232.

(15) Frogneux, X.; Jacquet, O.; Cantat, T. Iron-Catalyzed Hydrosilylation of $\mathrm{CO}_{2}$ : $\mathrm{CO}_{2}$ Conversion to Formamides and Methylamines. Catal. Sci. Technol. 2014, 4, 1529-1533.

(16) Riduan, S. N.; Ying, J. Y.; Zhang, Y. Solid Poly-N-Heterocyclic Carbene Catalyzed CO2 Reduction with Hydrosilanes. J. Catal. 2016, $343,46-51$.

(17) Jacquet, O.; Das Neves Gomes, C.; Ephritikhine, M.; Cantat, T. Complete Catalytic Deoxygenation of CO 2 into Formamidine Derivatives. ChemCatChem 2013, 5, 117-120.

(18) Das, S.; Bobbink, F. D.; Laurenczy, G.; Dyson, P. J. Metal-Free Catalyst for the Chemoselective Methylation of Amines Using Carbon Dioxide as a Carbon Source. Angew. Chem., Int. Ed. 2014, 53, $12876-$ 12879.

(19) Nicholls, R. L.; McManus, J. A.; Rayner, C. M.; Morales-Serna, J. A.; White, A. J. P.; Nguyen, B. N. Guanidine-Catalyzed Reductive Amination of Carbon Dioxide with Silanes: Switching between Pathways and Suppressing Catalyst Deactivation. ACS Catal. 2018, 8, $3678-3687$.

(20) Zhou, H.; Wang, G.-X.; Zhang, W.-Z.; Lu, X.-B. CO 2 Adducts of Phosphorus Ylides: Highly Active Organocatalysts for Carbon Dioxide Transformation. ACS Catal. 2015, 5, 6773-6779.

(21) Chong, C. C.; Kinjo, R. Hydrophosphination of $\mathrm{CO}_{2}$ and Subsequent Formate Transfer in the 1,3,2-DiazaphospholeneCatalyzed $N$-Formylation of Amines. Angew. Chem., Int. Ed. 2015, 54, 12116-12120.

(22) Liu, X.-F.; Qiao, C.; Li, X.-Y.; He, L.-N. Carboxylate-Promoted Reductive Functionalization of $\mathrm{CO}_{2}$ with Amines and Hydrosilanes under Mild Conditions. Green Chem. 2017, 19, 1726-1731.

(23) Li, X.-Y.; Zheng, S.-S.; Liu, X.-F.; Yang, Z.-W.; Tan, T.-Y.; Yu, A.; He, L.-N. Waste Recycling: Ionic Liquid-Catalyzed 4-Electron Reduction of $\mathrm{CO} 2$ with Amines and Polymethylhydrosiloxane Combining Experimental and Theoretical Study. ACS Sustainable Chem. Eng. 2018, 6, 8130-8135.

(24) Fang, C.; Lu, C.; Liu, M.; Zhu, Y.; Fu, Y.; Lin, B.-L. Selective Formylation and Methylation of Amines Using Carbon Dioxide and Hydrosilane Catalyzed by Alkali-Metal Carbonates. ACS Catal. 2016, 6, 7876-7881.

(25) Hao, L.; Zhao, Y.; Yu, B.; Yang, Z.; Zhang, H.; Han, B.; Gao, X.; Liu, Z. Imidazolium-Based Ionic Liquids Catalyzed Formylation of Amines Using Carbon Dioxide and Phenylsilane at Room Temperature. ACS Catal. 2015, 5, 4989-4993.

(26) Hulla, M.; Bobbink, F. D.; Das, S.; Dyson, P. J. Carbon Dioxide Based N-Formylation of Amines Catalyzed by Fluoride and Hydroxide Anions. ChemCatChem 2016, 8, 3338-3342.

(27) Das Neves Gomes, C.; Jacquet, O.; Villiers, C.; Thuéry, P.; Ephritikhine, M.; Cantat, T. A Diagonal Approach to Chemical Recycling of Carbon Dioxide: Organocatalytic Transformation for the Reductive Functionalization of CO2. Angew. Chem., Int. Ed. 2012, 51, 187-190.

(28) Frogneux, X.; Blondiaux, E.; Thuéry, P.; Cantat, T. Bridging Amines with $\mathrm{CO} 2$ : Organocatalyzed Reduction of $\mathrm{CO} 2$ to Aminals. ACS Catal. 2015, 5, 3983-3987.

(29) Song, J.; Zhou, B.; Liu, H.; Xie, C.; Meng, Q.; Zhang, Z.; Han, B. Biomass-Derived $\gamma$-Valerolactone as an Efficient Solvent and Catalyst for the Transformation of $\mathrm{CO}_{2}$ to Formamides. Green Chem. 2016, 18, 3956-3961.

(30) Lv, H.; Xing, Q.; Yue, C.; Lei, Z.; Li, F. Solvent-Promoted Catalyst-Free N-Formylation of Amines Using Carbon Dioxide under Ambient Conditions. Chem. Commun. 2016, 52, 6545-6548.

(31) Liu, X.-F.; Li, X.-Y.; Qiao, C.; Fu, H.-C.; He, L.-N. Betaine Catalysis for Hierarchical Reduction of $\mathrm{CO}_{2}$ with Amines and 
Hydrosilane To Form Formamides, Aminals, and Methylamines. Angew. Chem., Int. Ed. 2017, 56, 7425-7429.

(32) Wang, B.; Cao, Z. Sequential Covalent Bonding Activation and General Base Catalysis: Insight into N-Heterocyclic Carbene Catalyzed Formylation of $\mathrm{N}-\mathrm{H}$ Bonds Using Carbon Dioxide and Silane. RSC Adv. 2013, 3, 14007.

(33) Liu, X.-F.; Ma, R.; Qiao, C.; Cao, H.; He, L.-N. FluorideCatalyzed Methylation of Amines by Reductive Functionalization of $\mathrm{CO}_{2}$ with Hydrosilanes. Chem. - Eur. J. 2016, 22, 16489-16493.

(34) Li, W.; Kim, C. K. A. Theoretical Study on the Mechanism of Methylation of $\mathrm{N}$-Methylaniline with $\mathrm{CO}_{2}$ and Silyl Hydrides. Bull. Korean Chem. Soc. 2017, 38, 12-18.

(35) Zhou, Q.; Li, Y. The Real Role of N-Heterocyclic Carbene in Reductive Functionalization of CO2: An Alternative Understanding from Density Functional Theory Study. J. Am. Chem. Soc. 2015, 137, 10182-10189.

(36) Li, W.; Kim, C. K. Theoretical Investigations on the Methylation of $\mathrm{NH}$ Bond Using $\mathrm{CO} 2$ and Hydrosilane Catalyzed by ZincII Complexes: Mechanism and Ligand Effect. $J . \mathrm{CO}_{2}$ Util. 2017, 20, 178-189.

(37) Riduan, S. N.; Zhang, Y.; Ying, J. Y. Conversion of Carbon Dioxide into Methanol with Silanes over N-Heterocyclic Carbene Catalysts. Angew. Chem., Int. Ed. 2009, 48, 3322-3325.

(38) Motokura, K.; Naijo, M.; Yamaguchi, S.; Miyaji, A.; Baba, T. Reductive Transformation of $\mathrm{CO} 2$ with Hydrosilanes Catalyzed by Simple Fluoride and Carbonate Salts. Chem. Lett. 2015, 44, 12171219.

(39) Julián, A.; Guzmán, J.; Jaseer, E. A.; Fernández-Alvarez, F. J.; Royo, R.; Polo, V.; García-Orduña, P.; Lahoz, F. J.; Oro, L. A. Mechanistic Insights on the Reduction of $\mathrm{CO}_{2}$ to Silylformates Catalyzed by Ir-NSiN Species. Chem. - Eur. J. 2017, 23, 1189811907.

(40) Revunova, K.; Nikonov, G. I. Base-Catalyzed Hydrosilylation of Ketones and Esters and Insight into the Mechanism. Chem. - Eur. J. 2014, 20, 839-845.

(41) Buslov, I.; Keller, S. C.; Hu, X. Alkoxy Hydrosilanes As Surrogates of Gaseous Silanes for Hydrosilylation of Alkenes. Org. Lett. 2016, 18, 1928-1931.

(42) Chauhan, M.; Chauhan, B. P. S.; Boudjouk, P. An Efficient PdCatalyzed Route to Silyl Esters. Org. Lett. 2000, 2, 1027-1029.

(43) Mellmann, D.; Sponholz, P.; Junge, H.; Beller, M. Formic Acid as a Hydrogen Storage Material - Development of Homogeneous Catalysts for Selective Hydrogen Release. Chem. Soc. Rev. 2016, 45, 3954-3988.

(44) Dutcher, B.; Fan, M.; Russell, A. G. Amine-Based $\mathrm{CO}_{2}$ Capture Technology Development from the Beginning of 2013-A Review. ACS Appl. Mater. Interfaces 2015, 7, 2137-2148.

(45) Das, S.; Bobbink, F. D.; Bulut, S.; Soudani, M.; Dyson, P. J. Thiazolium Carbene Catalysts for the Fixation of $\mathrm{CO} 2$ onto Amines. Chem. Commun. 2016, 52, 2497-2500.

(46) Itagaki, S.; Yamaguchi, K.; Mizuno, N. Catalytic Synthesis of Silyl Formates with 1 Atm of CO2 and Their Utilization for Synthesis of Formyl Compounds and Formic Acid. J. Mol. Catal. A: Chem. 2013, 366, 347-352.

(47) Knausz, D.; Meszticzky, A.; Szakacs, L.; Csakvari, B.; Ujszaszy, K. Trimethylsilylated N- Alkyl-Substituted Carbamates I.Preparation and Some Reactions. J. Organomet. Chem. 1983, 256, 11-21.

(48) Rohonczy, J.; Knausz, D.; Csákvári, B.; Sohár, P.; Pelczer, I.; Párkányi, L. Trimethylsilylated N-Alkyl-Substituted Carbamates: III. Structure of Trimethylsilyl-N,N-Diisopropyl Carbamate in Solid Phase and in Solution. J. Organomet. Chem. 1988, 340, 293-302.

(49) Baines, J. E.; Eaborn, C. Organosilicon Compounds. Part XVI. The Alkaline Hydrolysis of Triorganomonosilanes. J. Chem. Soc. 1956, 1436-1441.

(50) Kaplan, L.; Wilzbach, K. E. Hydrogen Isotope Effects in the Alkaline Cleavage of Triorganosilanes 1. J. Am. Chem. Soc. 1955, 77, 1297-1302.

(51) Kraushaar, K.; Schmidt, D.; Schwarzer, A.; Kroke, E. Reactions of $\mathrm{CO} 2$ and $\mathrm{CO} 2$ Analogs (CXY with X, Y = O, S, NR) with Reagents
Containing $\mathrm{Si}-\mathrm{H}$ and $\mathrm{Si}-\mathrm{N}$ Units. Adv. Inorg. Chem. 2014, 66, 117162.

(52) Knausz, D.; Meszticzky, A.; Szakács, L.; Csákvári, B. Trimethylsilylated N-Alkyl-Substituted Carbamates: II. Alcoholysis of Trimethylsilyl N,N-Dimethylcarbamate. J. Organomet. Chem. 1984, 268, 207-211. 